\title{
25 Research Soure \\ Comparison of Conventional and Hybrid Ultrasonic Milling in the Processing of Improved Steel
}

Borislav Savkovic ( $\nabla$ savkovic@uns.ac.rs)

University of Novi Sad https://orcid.org/0000-0002-9037-2179

Nenad Kulundzic

University of Novi Sad

Pavel Kovac

University of Novi Sad

\section{Research Article}

Keywords: Machinability, Milling, Hybrid process, Ultrasonic milling, Surface quality, surface roughness

Posted Date: February 12th, 2021

DOI: https://doi.org/10.21203/rs.3.rs-189929/v1

License: (1) This work is licensed under a Creative Commons Attribution 4.0 International License.

Read Full License 
Noname manuscript No.

(will be inserted by the editor)

\title{
Comparison of conventional and hybrid ultrasonic milling in the processing of improved steel

\author{
Do you have a subtitle?
} \\ If so, write it here
}

\author{
Borislav Savković • Nenad Kulundžić • Pavel Kovač \\ Faculty of Technical Sciences, University of Novi Sad, 21000 Novi Sad, Serbia. Tel: +381-21-4852329; Fax: \\ +381 21-454495; E-mail: savkovic@uns.ac.rs; kulundzic@uns.ac.rs; pkovac@uns.ac.rs.
}

Received: date / Accepted: date

\begin{abstract}
The combination of conventional milling and ultrasonic processing, more precisely ultrasonic vibrations, belongs to the newer types of hybrid processing. The realization of vibration sources as well as parameters that are variable in the realization of this process capture the attention of readers. In this paper, in addition to the application and possibility of installing different types of ultrasonically supported milling, the emphasis is given in the field of the surface quality. Namely, the application of ultrasonic vibrations in the processing of steel for improvement, which are characterized by higher hardness and toughness, and as such are a challenge for finding the most favorable processing. The quality of the processed surface as a function of the mean arithmetic roughness and the mean height of the unevenness measured in 10 points obtained in the classical conventional milling and the new hybrid process are presented.
\end{abstract}

Keywords Machinability · Milling · Hybrid process - Ultrasonic milling · Surface quality · surface roughness.

\section{Introduction}

In the modern machine industry, which is developing rapidly, the demand for higher quality products is growing day by day, with the shortest possible production time. This means that it is necessary to take into account the adequate choice of materials as well as the accuracy of workmanship, the achieved quality of the machined surface and other output characteristics.
Modern machine materials that possess superior mechanical properties, such as Inconel 718, AISI 420 stainless steel, glass-ceramics, titanium alloys, nickel-based superalloys, etc. are widely used in the aerospace, rocket (space), automotive and other industries, mostly in extreme working conditions, such as elevated temperatures, corrosive environments, for responsible parts, parts under constant load, etc. Of course, such long-lasting and high-quality materials are very difficult to process, and thus represent a huge problem with conventional processing procedures. This problem has conditioned the intensification of hybrid processing, i.e., the combination of conventional processing with unconventional processes. One of the many hybrid machining processes, which was the topic of this paper, is ultrasound-assisted milling (UAM). The essence of this processing is to bring to the tool or workpiece ultrasonic vibration, small amplitude, of the order of $\mu \mathrm{m}$ or $\mathrm{nm}$, and high frequency, of the order of $\mathrm{kHz}$. Many experimental studies, some of which have been exhibited, have indicated the suitability and improvement of the output characteristics of this treatment compared to conventional milling.

\section{$2 \quad$ Milling processing}

Due to its universality and productivity, milling is one of the most common cutting technologies. Milling is a process of processing flat surfaces, profiled contours, grooves, surfaces of complex and special shape. A large number of scientific researches is focused on daily improvement of this process [1]. 


\subsection{Ultrasonic assisted milling}

In the machine industry, milling processing technology is the most common process of material removal due to a number of conveniences. As we strive for the most accurate machining possible, it is necessary to increase the values of machining parameters, such as cutting speed, feed per tooth and cutting depth. With the increase of the value of the processing parameters, a higher thermal energy is generated, i.e., temperature. High cutting temperature adversely affects the quality of the machined surface as well as the durability of the tool.

Ultrasonic Machining (USM) is an unconventional processing procedure, and it has found its application for dimensional processing of hard and brittle materials. In addition, ultrasonic processing is also used to remove traces of previous processing - polishing, rounding sharp edges, cleaning parts, etc. Ultrasound accelerates its application every day, so we have its presence in ultrasonically supported scraping, drilling or milling. Of course, the application is not limited to the field of chip removal, but is also present in other machine processes such as welding, casting and plastic deformation [2].

Ultrasound is elastic waves that propagate at a certain speed through a gaseous, liquid and solid medium, a certain amplitude of oscillations and wavelength. Ultrasound is sound generated above the range of human hearing; whose frequency is usually over $20 \mathrm{kHz}$. Figure 1 shows a comparison of the frequency and amplitude of sound and ultrasound.

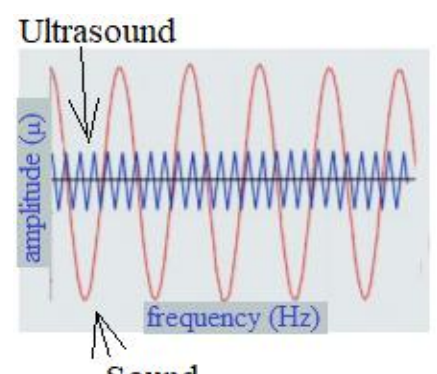

Sound

Fig. 1 Frequency and amplitude in ultrasonic processing

The speed of propagation of sound oscillations c, depends on the frequency of oscillation $f$ and the length of the sound wave $\lambda$, ie. periods of oscillation $\mathrm{T}$, is expressed: $c=\lambda \cdot f=\frac{\lambda}{T}$

Ultrasound is considered to be mechanical oscillations of high frequencies, which are obtained by means of an electroacoustic transducer - oscillator. In the oscillator, the electrical energy obtained from the high-frequency generator is converted into sound energy, i.e., in mechanical oscillatory motion. There are two types of oscillators, the magneto strictive and the piezoelectric oscillator. Ultrasonic assisted milling (UAM) is an advanced machining process that combines ultrasonic vibration as an auxiliary mechanism in the milling process. Various studies have shown that ultrasonic-assisted cutting contributes to a reduction in cutting temperature and force, due to less contact friction between the tool and the workpiece. This provides a higher durability which can be up to $40 \%$ higher, while the surface roughness can be reduced by up to two times. Today, a vibrating mechanism can be installed directly on a cutting tool or on a workbench. Vibration is one of the mechanisms that can be used to support the processing. Vibration is the oscillation of a body around its static, i.e., around the equilibrium position. When a small-amplitude vibration is applied to a cutting tool or workpiece, it has a positive effect on the machining process compared to the same, conventional process.

Figure 2 shows a schematic of the basic elements of a USM device. High-frequency electrical energy can be converted into mechanical vibrations with a resonant frequency via a converter. Piezoelectric actuator is one of the devices that can produce a precise vibration amplitude (order of magnitude $\mu \mathrm{m}$ or $\mathrm{nm}$ ) of high frequency (order of magnitude $\mathrm{kHz}$ ) [3]. The excited vibration is then transmitted through an amplifier of ultrasonic oscillations - a concentrator or booster. Thus, the amplified vibration amplitude is brought to the top of the tool, i.e., the sonotrode. Such vibration is further transmitted via the sonotrode to the workpiece by means of a vibratory plate which is attached to the table of the machine tool, i.e., the milling machine. 


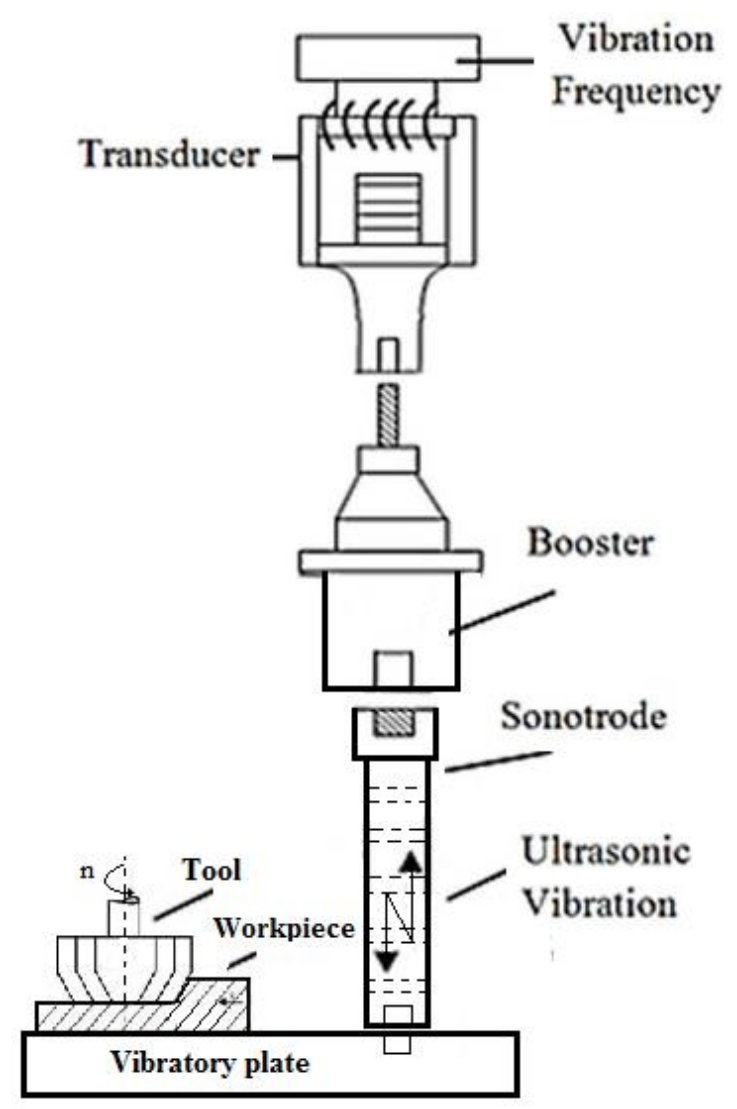

Fig. 2 Components of an ultrasonic system for hybrid milling

2.2 The use of ultrasound assisted milling

In the literature there are experiments on frequently used industrial materials such as: titanium alloys, glass-ceramics, Inconel 718, AISI 420 stainless steel, aluminum alloys, glass, several of which will be attached below [4-7].

\subsubsection{The influence of the rotary ultrasonic elliptical side milling (RUEM) on the integrity of the surface of the Ti-6Al-4V}

The titanium alloy Ti-6Al-4V is an extremely attractive material used in the aerospace industry due to its power-to-weight ratio, corrosion resistance and fatigue. However, due to poor machinability, Ti-6Al-4V is susceptible to surface damage and has low fatigue strength during machining. Surface integrity has an important impact on the performance, reliability and durability of manufactured components. In the paper [4], the experiment was performed on a four-axis CNC milling machine (BV100) equipped with a tool holder with ultrasonic ellipsoid vibrations. The influence of the cutting speed and feed per tooth to the surface roughness is shown in Figure 3. The figure shows that a better roughness of the machined surface is obtained during conventional milling $(\mathrm{CM})$.

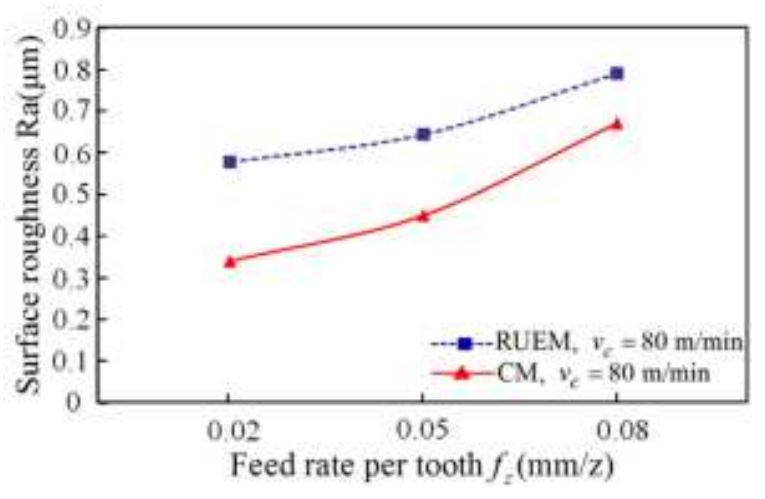

Fig. 3 Influence of feed per tooth on the surface roughness [4]

In addition to this negative effect in terms of surface roughness, the authors also acknowledged the positive contribution of RUEM. The values of residual compressive stresses in Rotary Ultrasonic Elliptical Milling (RUEM) can change in a narrow range by varying the vibration frequency and are lower than in CM.

\subsubsection{Influence of ultrasound-assisted milling in glass-ceramic processing}

In glass-ceramic cutting processes, high temperature quickly accumulates around the cutting edge of the tool due to the contact between the workpiece and the tool as well as due to the very poor thermal conductivity of the workpiece. Figure 4 shows a comparison of edge wear and tool wear versus feed per tooth with and without UAM, in the use of the cutting fluid of a water soluble [5].

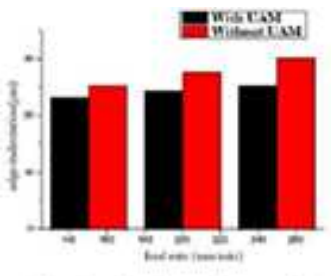

(a) edge-indentation vs $\mathrm{F}$

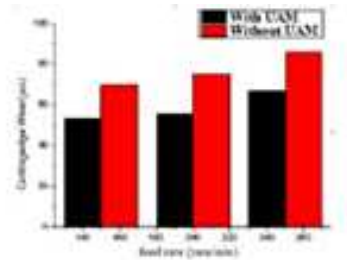

(b) cutting-tool wear vs $\mathrm{F}$
Fig. 4 Comparison of edge wear and tool wear 


\subsubsection{Feasibility of ultrasonically assisted milling for component processing in the aerospace industry}

Superalloys have found their suitability for making parts designed to work in extreme conditions. More than $80 \%$ of the use of superalloys such as Inconel 718 and titanium are found in the aerospace industry [6]. The cutting force is a key variable that is used as an indicator of tool wear among indirect wear monitoring methods. When investigating the machinability of the super hard Inconel alloy, the authors showed that the lateral wear of the tool was drastically reduced in the UAM process.

\subsubsection{Influence of ultrasonic vibrations on lateral milling of AISI 420 stainless steel}

AISI 420 martensitic stainless steel is widely used in places where a combination of corrosion resistance and high strength is required, such as turbine blades, shafts, propellers and surgical instruments [7]. In this experimental model, the cutting force of one-way UAM was presented and ultrasound-assisted milling was applied to examine the cutting force and the quality of the machined surface under different cutting conditions. It was shown that the cutting forces in UAM were less than in $\mathrm{CM}$, and for the shift $\mathrm{f}_{\mathrm{z}}=0.05 \mathrm{~mm} / \mathrm{t}$ they were reduced by $19 \%$.

Based on the literature reviews, it is not possible to say definitively what the impact of ultrasound is in terms of the quality of the machined surface. That is, different materials give different characteristics of the roughness of the machined surface. In addition, the choice of vibrations in terms of orthogonal orientation is also a parameter that certainly affects the quality of the cut, and thus the resulting machining surface. All these factors encourage further research in the field of application and analysis of ultrasound-assisted milling.

\section{Experimental part}

The practical part of this paper is an experiment performed on a vertical milling machine Deckel Maho FP3-50. In this experiment, a version of UAM was adopted, where vibration is applied to a working object, steel to improve EN 42CrMo4.
The aim of the experiment was to compare the output characteristics, mean arithmetic roughness and mean height of the unevenness measured in 10 points, between conventional milling and ultrasound - assisted milling.

Used head for face milling "TBAP16 90 D 63-6, with mechanically fastened cutting inserts, with the following characteristics: milling diameter 63 $\mathrm{mm}$, number of teeth $(\mathrm{t}=6)$, angle of attack $\kappa=$ $90^{\circ}$. As cutting tools were used cutting tiles company TaeguTec, tags Apkte 1604 RRE TT9080, coated with AlTiN-TiN with PVD process. All experiments were performed with a single-toothed tool, i.e., with one cutting insert ( $t$ $=1$ ), Figure 5 .

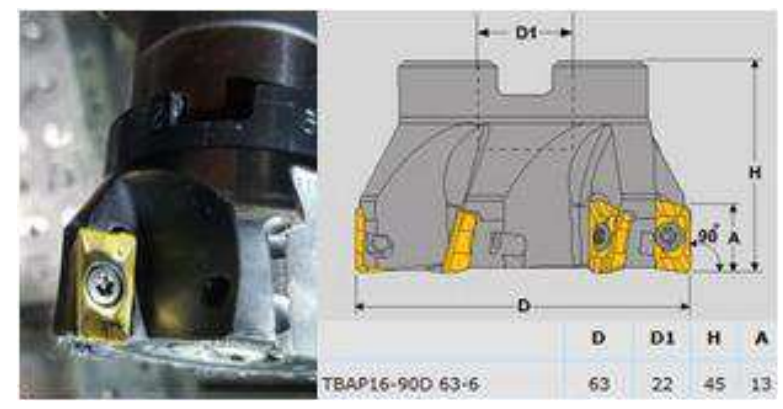

Fig. 5 Cutting tool with milling head

The chemical composition of the EN 42CrMo4 workpiece and the mechanical properties are given in Table 1.

Table 1 Chemical composition and mechanical properties of steel for improvement EN 42CrMo4

\begin{tabular}{|c|c|c|c|}
\hline $\begin{array}{l}\text { Chemical } \\
\text { element }\end{array}$ & $\begin{array}{c}\text { Share } \\
{[\%]}\end{array}$ & $\begin{array}{l}\text { Material } \\
\text { property }\end{array}$ & Value \\
\hline $\mathrm{C}$ & 0,40 & \multirow{2}{*}{$\begin{array}{l}\text { Yield strength } \\
\mathrm{R}_{\mathrm{p} 0,2 \%}(\mathrm{MPa})\end{array}$} & \multirow{2}{*}{790} \\
\hline $\mathrm{Si}$ & 0,427 & & \\
\hline $\mathrm{Mn}$ & 0,497 & \multirow{2}{*}{$\begin{array}{c}\text { Tensile strength } \\
\mathrm{R}_{\mathrm{m}}(\mathrm{MPa})\end{array}$} & \multirow{2}{*}{975} \\
\hline $\mathrm{S}$ & 0,042 & & \\
\hline $\mathrm{P}$ & 0,039 & \multirow{2}{*}{$\begin{array}{c}\text { Elongation } \\
\mathrm{A}(\%)\end{array}$} & \multirow{2}{*}{16,4} \\
\hline $\mathrm{Cr}$ & 0,914 & & \\
\hline $\mathrm{Mo}$ & 0,183 & \multirow{2}{*}{$\begin{array}{c}\text { Contraction } \\
\mathrm{Z}(\%) \\
\end{array}$} & \multirow{2}{*}{43} \\
\hline $\mathrm{Ni}$ & 0,35 & & \\
\hline $\mathrm{Cu}$ & 0,17 & Hardness & \multirow{2}{*}{265} \\
\hline $\bar{V}$ & 0,01 & $\mathrm{HB}$ & \\
\hline
\end{tabular}

The generator used for this experiment was manufactured by MPI, power $2 \mathrm{~kW}$, shown in Figure 6a). The high-frequency generator sends oscillator electricity, which is converted into 
mechanical vibration by a converter and a sonotrode and brought to the workpiece. Between the workbench and the workpiece is a vibrating plate, Figure 6b). The vibrating plate has the ability to accept the sonotrode in three orthogonal directions. In this experimental procedure, the research was performed in the direction of the $\mathrm{Z}$ axis. The parameters that the generator works on are monitored using the Ultrasonic Cleaning Generator DSS software, which has the ability to graphically monitor defined values.
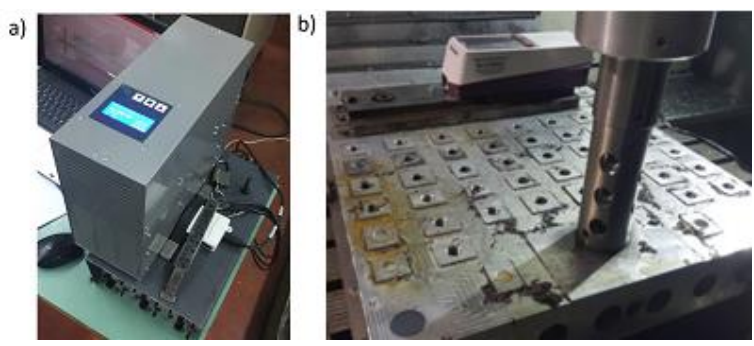

Fig. 6 a) high frequency generator and b) vibrating plate

In addition to the vibrating plate (made of Al7075) in the shown assembly, the central place is occupied by vibrating carriers (made of 316L stainless steel) which aim to prevent further transmission of vibrations to the milling table.

Figure 7 shows the value of the generator parameters, controlled by the specified software.

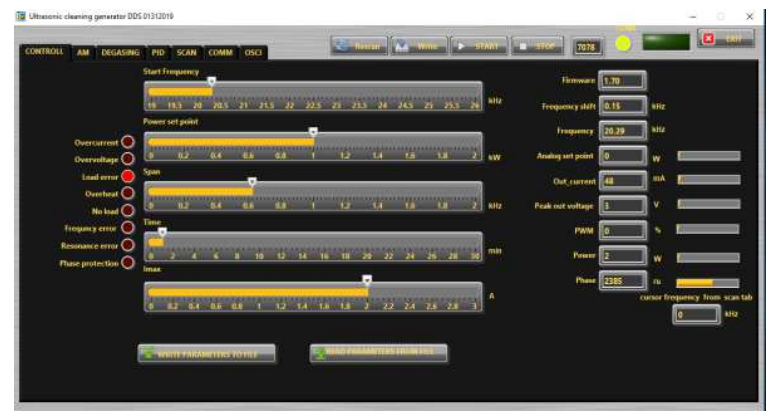

Fig. 7 Ultrasonic Cleaning Generator DSS

For the purposes of this research, ie. to measure the roughness of the machined surface, the Mitutoyo Surftest SJ-210 device was used, with a measuring range of $360 \mu \mathrm{m}(-200 \mu \mathrm{m}$ to $160 \mu \mathrm{m})$. Table 2 shows the constant parameters of the experiment as well as the range in which the variable input parameters were varied. The experiment was performed without coolant and lubricant.
Table 2 Experiment parameters

\begin{tabular}{|c|c|c|c|c|}
\hline Parameter & \multicolumn{4}{|c|}{ Value } \\
\hline Power $[\mathrm{kW}]$ & \multicolumn{4}{|c|}{2} \\
\hline Amplitude $[\mu \mathrm{m}]$ & \multicolumn{4}{|c|}{$10 \div 15$} \\
\hline Frequency [kHz] & \multicolumn{4}{|c|}{19.45} \\
\hline $\begin{array}{l}\text { Cutting depth } \\
{[\mathrm{mm}]}\end{array}$ & \multicolumn{4}{|c|}{0.5} \\
\hline $\begin{array}{l}\text { Feed per tooth } \\
{[\mathrm{mm} / \mathrm{t}]}\end{array}$ & 0,35 & & & 0,7 \\
\hline $\begin{array}{l}\text { Cutting speed } \\
{[\mathrm{m} / \mathrm{s}]}\end{array}$ & 0,231 & 0,294 & 0,462 & 0,561 \\
\hline
\end{tabular}

\section{Results and Discussion}

The measurement of the roughness of the machined surface was performed in the direction of movement of the milling table, with a measuring range of $12.5 \mathrm{~mm}$, which can be set on the device Surftest SJ-210, in Figure 8.

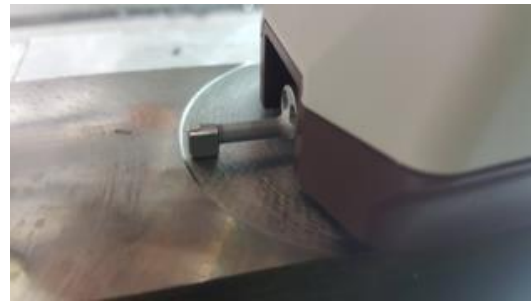

Fig. 8 Measurement of surface roughness by using Surftest device SJ-210

Figures 9, 10 and 11 show the obtained values of the mean arithmetic roughness $R_{a}$ at different cutting speeds obtained by conventional milling (CM) and ultrasound-assisted milling (UAM). Also, on each diagram there is a different feed per tooth, with values of $0.35 ; 0.55$; and 0.7 ; respectively.

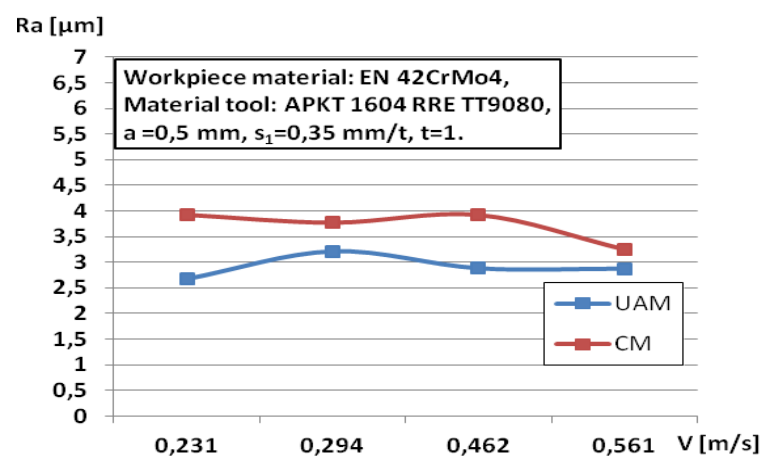

Fig. 9 Mean arithmetic roughness Ra as a function of 
different cutting speeds with a constant feed of $0.35 \mathrm{~mm} / \mathrm{t}$

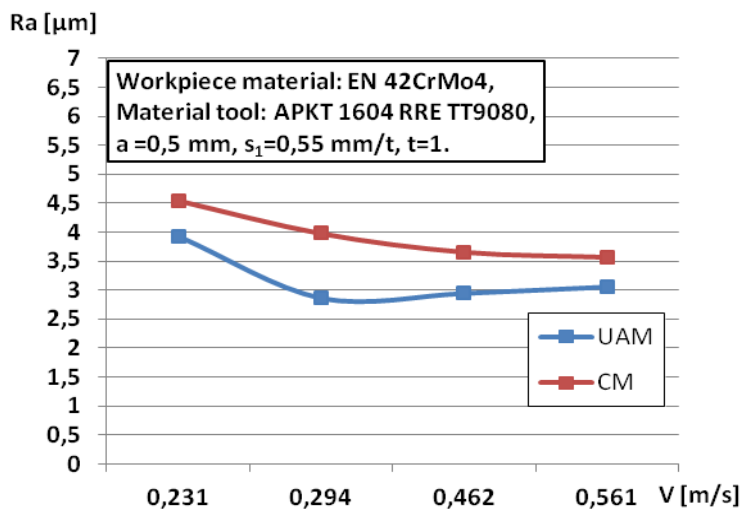

Fig. 10 Mean arithmetic roughness $\mathrm{Ra}$ as a function of different cutting speeds with a constant feed of $0.55 \mathrm{~mm} / \mathrm{t}$

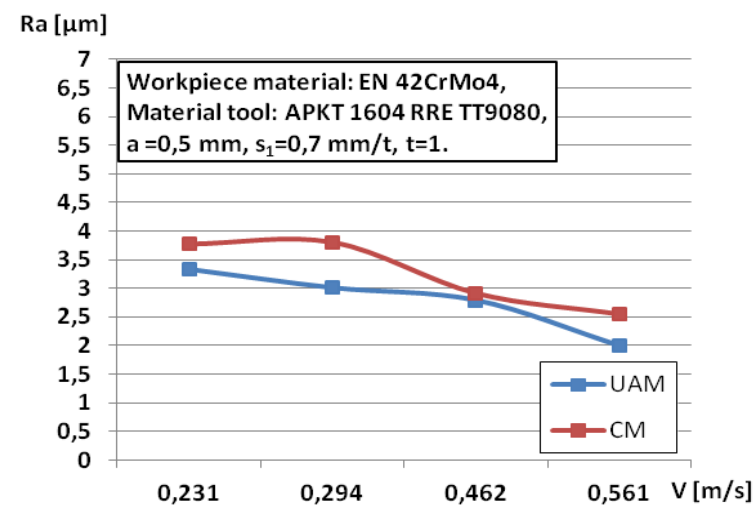

Fig. 11 Mean arithmetic roughness $\mathrm{Ra}$ as a function of different cutting speeds with a constant feed of $0.7 \mathrm{~mm} / \mathrm{t}$

It can be clearly seen from the figures that better roughness values are achieved at UAM, and in general the roughness decreases with increasing cutting speed.

It is also possible to analyze the roughness with other parameters, so Figures 12, 13 and 14 show the value of the obtained mean height of the unevenness measured at 10 points $R_{\%}$. The diagrams are created according to the same principle as for the value of $R_{a}$.

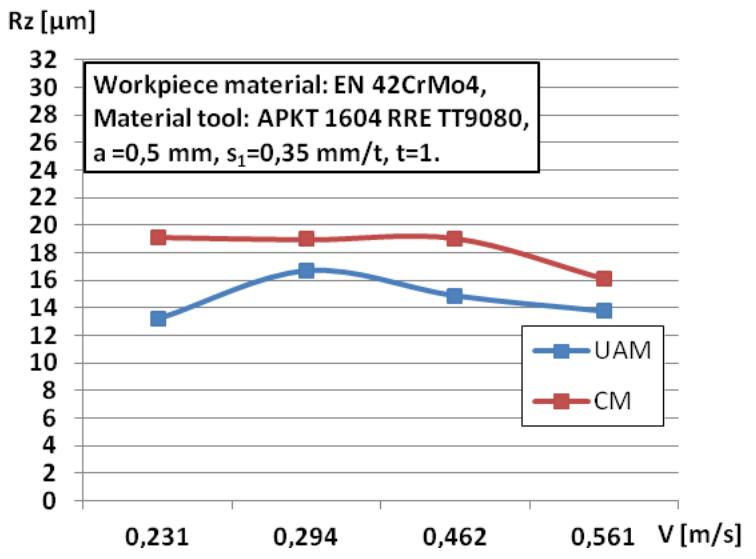

Fig. 12 Mean height of unevenness measured at ten points $\mathrm{Rz}$ as a function of different cutting speeds with a constant feed of $0.35 \mathrm{~mm} / \mathrm{t}$

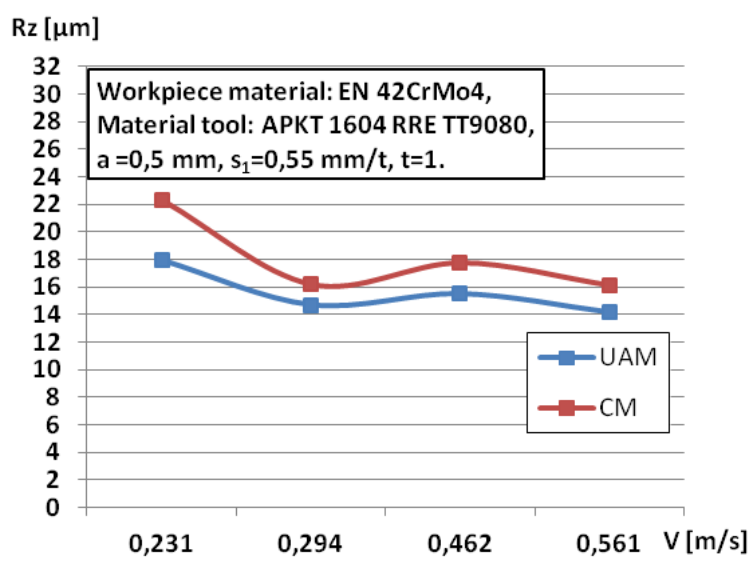

Fig. 13 Mean height of unevenness measured at ten points $\mathrm{Rz}$ as a function of different cutting speeds with a constant feed of $0.55 \mathrm{~mm} / \mathrm{t}$

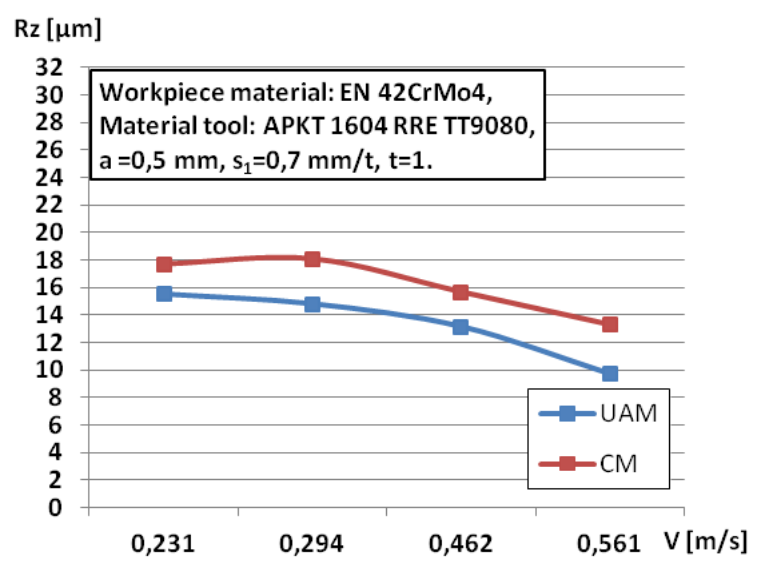

Fig. 14 Mean height of unevenness measured at ten points Rz as a function of different cutting speeds with a constant feed of $0.7 \mathrm{~mm} / \mathrm{t}$

From Figures 12, 13 and 14 it can also be seen 
that less roughness was achieved in UAM processing compared to CM. It should be noted that only the minimum cutting speeds were varied in the experiment due to the fact that at higher speeds the cutting edge is damaged due to elevated cutting temperatures. It can be concluded that the experimental design brings lower roughness when processing steel for improve EN 42CrMo4, which was not the case in [4]. Figures 15 and 16 show diagrams showing the influence of feed per tooth from the aspect of UAM application as a function of different cutting speeds.

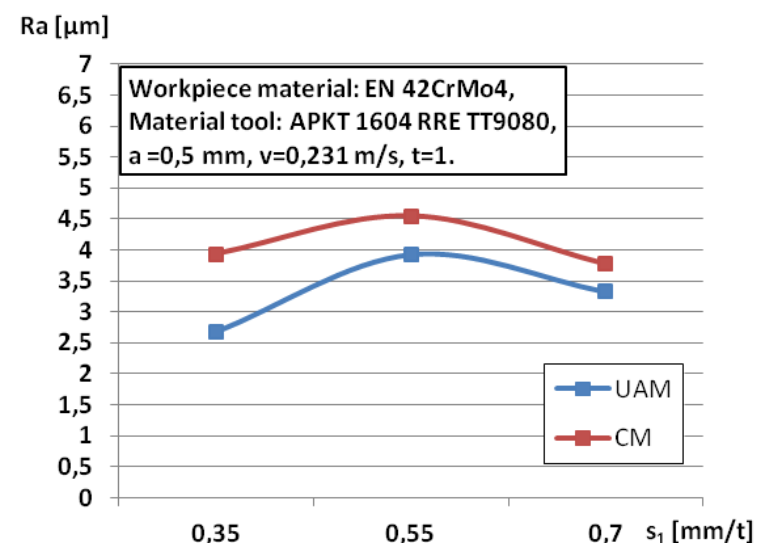

Fig. 15 Mean arithmetic roughness $\mathrm{Ra}$ as a function of different feed per tooth and constant cutting speed

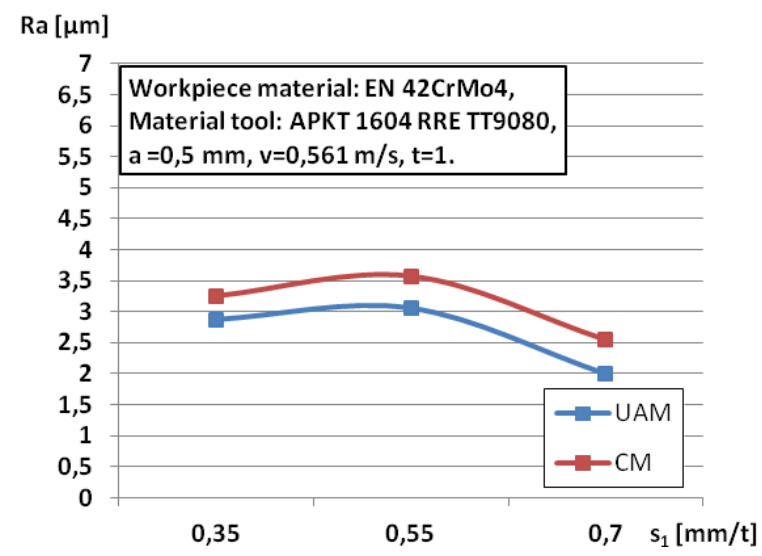

Fig. 16 Mean arithmetic roughness Ra as a function of different feed per tooth and constant cutting speed

Based on Figure 15, which shows the dependence of the arithmetic mean roughness at the minimum cutting speed, it can be seen that the most favorable regimes are at the minimum feed per tooth with the use of UAM. However, when analyzing the roughness at the maximum cutting speed for $\mathrm{v}=0.561 \mathrm{~m} / \mathrm{s}$, Figure 16, the most favorable regime was obtained at the maximum feed per tooth, in the range tested in the attached experiment. At the same time, this mode represents the optimal solution for the entire plan of the experiment that was done.

\section{Conclusion}

With the development of the machine industry, the appetites of customers grow. Not only in terms of the time required to make the desired product and the quality of workmanship, but also in the choice of materials. New materials are appearing on the market with better mechanical properties, which makes their machinability more difficult. Hard-to-machine materials require enhanced working conditions that are placed in front of the machine, in the form of increased cutting forces, feed and cutting speeds. The increase in the operating conditions results in an increased operating temperature, which is very unfavorable influence on the output characteristics of the processing. Therefore, there is a tendency to intensify hybrid processing processes.

Processing of modern materials by conventional milling is possible, but at the cost of longer production time, intensive tool wear, reduced accuracy and quality of the processed surface, increased cutting forces and many other factors. To reduce these factors, there was a combination of two, conventional and unconventional machining processes, milling and ultrasonic machining, into one functional unit called ultrasound-assisted milling.

Some of the modern materials that have been processed by ultrasound-assisted milling are Inconel 718, AISI 420 stainless steel, titanium alloys, nickel-based superalloys, glass-ceramics and others. have given clear results on how a constant vibration supply can positively affect their machinability and the same output characteristics. The reason for this is that the vibration affects the more frequent separation of the contact surface of the tool - workpiece, and thus there is a better flow of coolant and lubricant and the removal of accumulated working heat.

In particular, when processing steel for improvement, it can be concluded that ultrasoundassisted milling is a good processing technology and that the best results are achieved at generally low cutting speeds. However, in this field of low speeds, the most favorable results are obtained at 
maximum feed with increased cutting speed.

This field of application of UAM is wide and raises the question of application in high-speed machining as well as in cutting at greater depths, which is a challenge for further research.

\section{Ethical Approval \\ Not applicable}

\section{Consent to Participate}

Not applicable

\section{Consent to Publish}

The authors agree to publish.

\section{Authors Contributions}

B.S. conceived of the presented idea. N.K. developed the theory and performed the experiments. P.K. supervised the findings of this work. All authors discussed the results and contributed to the final manuscript.

\section{Funding}

This research received no external funding

\section{Competing Interests}

The authors declares that he has no conflicts of interest.

Availability of data and materials

All data and materials generated or analyzed during this study are included in this article.

\section{References}

[1] B. Savkovic, P. Kovac, B. Dudic, M. Gregus, D. Rodic, B. Strbac and N. Ducic, "Comparative characteristics of ductile iron and austempered ductile iron modeled by neural network," Materials, vol. 12, no. 18, pp. 1-16, 2019.

[2] L. Balamuth, "Ultrasonic assistance to conventional metal removal," Ultrasonics, vol. 4, no. 3, pp. 125-130, 1966.
[3] R. Gaidys, O. Dambon, V. Ostasevicius, C. Dicke and B. Narijauskait, "Ultrasonic tooling system design and development for single point diamond turning (SPDT) of ferrous metals," The International Journal of Advanced Manufacturing Technology, vol. 93, no. 5-8, pp. 2841-2854, 2017.

[4] J. Liu, X. Jiang, X. Han, Z. Gao and D. Zhang, "Effects of rotary ultrasonic elliptical machining for side milling on the surface integrity of Ti-6Al-4V," The International Journal of Advanced Manufacturing Technology, vol. 101, no. 5-8, pp. 1451-1465, 2019.

[5] S. Y. Lin, C. H. Kuan, C. H. She and W. T. Wang, "Application of ultrasonic assisted machining technique for glass-ceramic milling," International Journal of Mechanical, Aerospace, Industrial, Mechatronic and Manufacturing Engineering, vol. 9, no. 5, pp. 802-807, 2015.

[6] M. S. A. Hafiz, M. H. A. Kawaz, W. N. F. Mohamad, M. S. Kasim, R. Izamshah, J. B. Saedon and S. B. Mohamed, "A review on feasibility study of ultrasonic assisted machining on aircraft component manufacturing," in IOP Conference Series: Materials Science and Engineering, Putrajaya, 2017.

[7] M. A. Zarchi, M. R. Razfar and A. Abdullah, "Influence of ultrasonic vibrations on side milling of AISI 420 stainless steel," The International Journal of Advanced Manufacturing Technology, vol. 66, no. 1-4, pp. 83-89, 2013.

Faculty of Technical Sciences, University of

Novi Sad, 21000 Novi Sad, Serbia

Tel: +381-21-4852329

Fax: +381 21-454495

E-mail: savkovic@uns.ac.rs

Faculty of Technical Sciences, University of Novi Sad, 21000 Novi Sad, Serbia. E-mail: kulundzic@uns.ac.rs; pkovac@uns.ac.rs 
Figures

Ultrasound

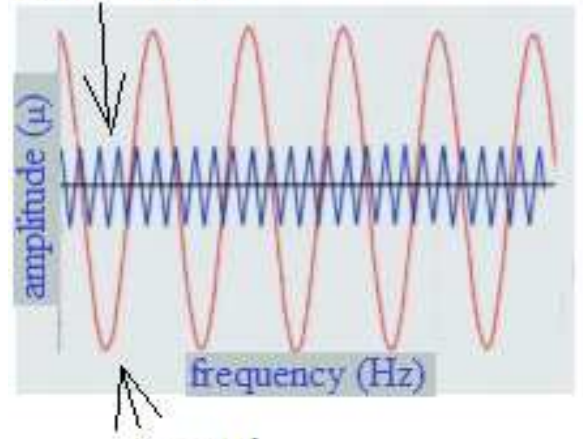

Sound

Figure 1

Frequency and amplitude in ultrasonic processing

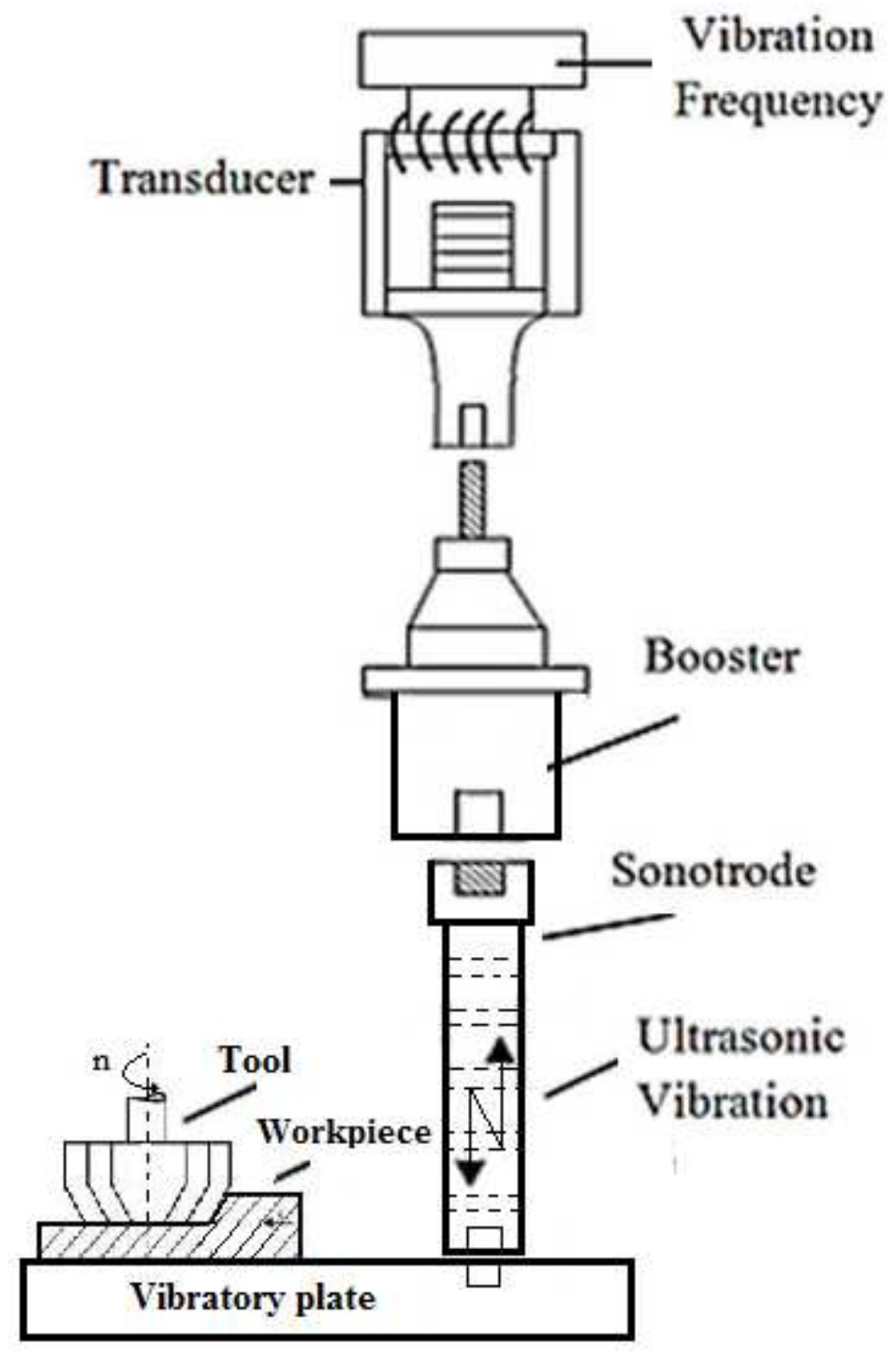

Figure 2 
Components of an ultrasonic system for hybrid milling

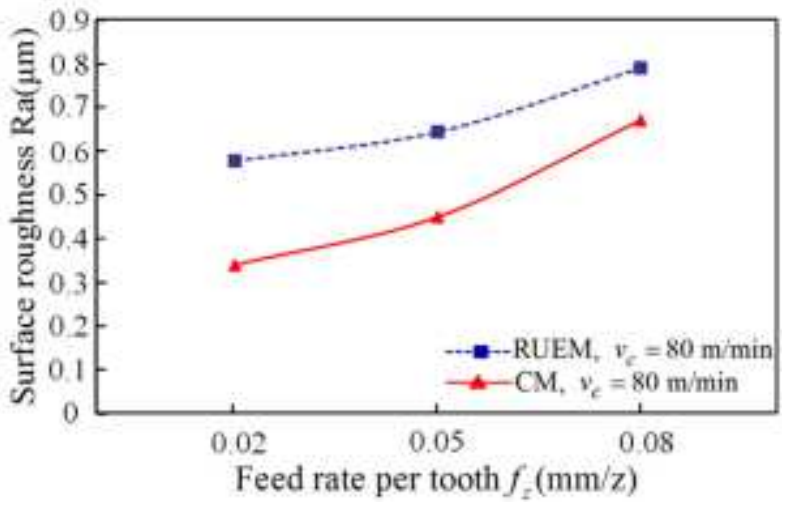

Figure 3

Influence of feed per tooth on the surface roughness [4]

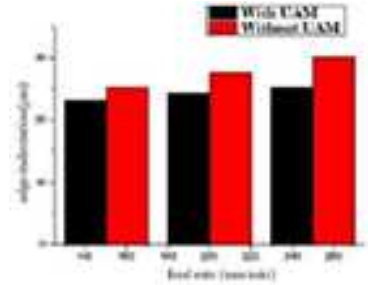

(a) edge-indentation vs $\mathrm{F}$

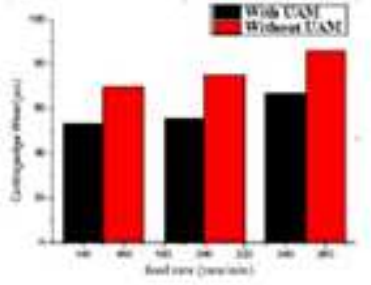

(b) cutting-tool wear vs $\mathrm{F}$

\section{Figure 4}

Comparison of edge wear and tool wear

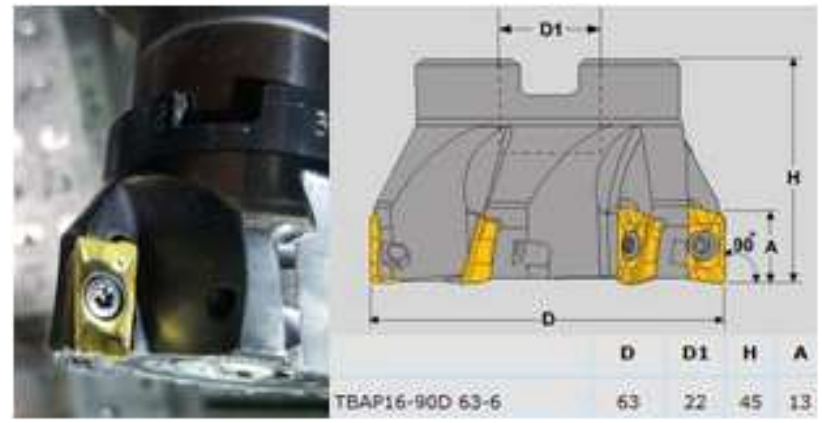

Figure 5

Cutting tool with milling head

a)

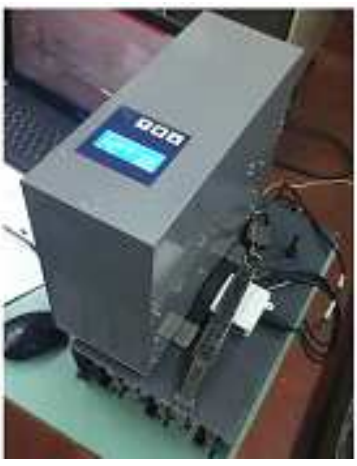

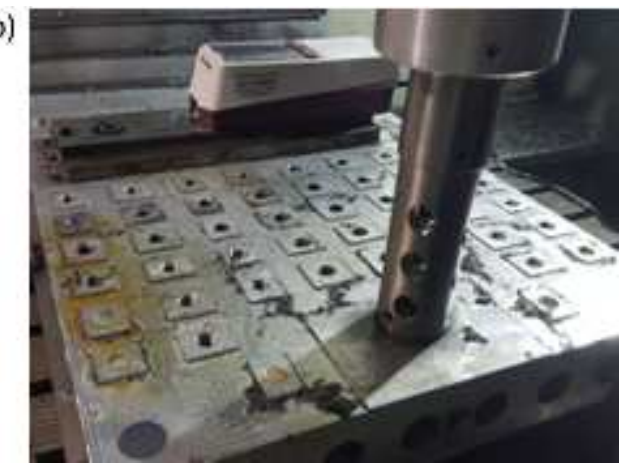


Figure 6

a) high frequency generator and b) vibrating plate

Ulitrasonic cleaning generator DDS 01312019

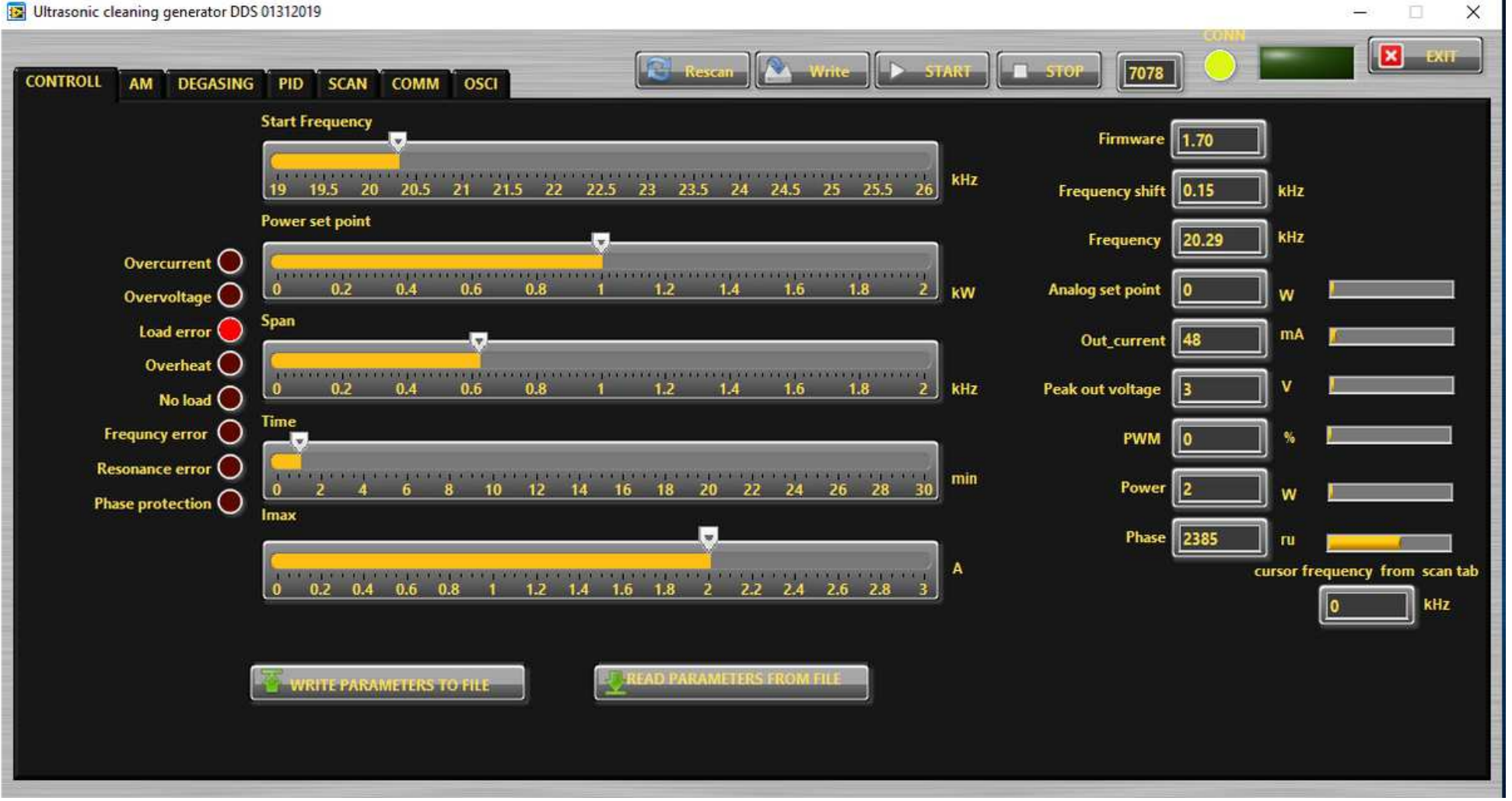

Figure 7

Ultrasonic Cleaning Generator DSS

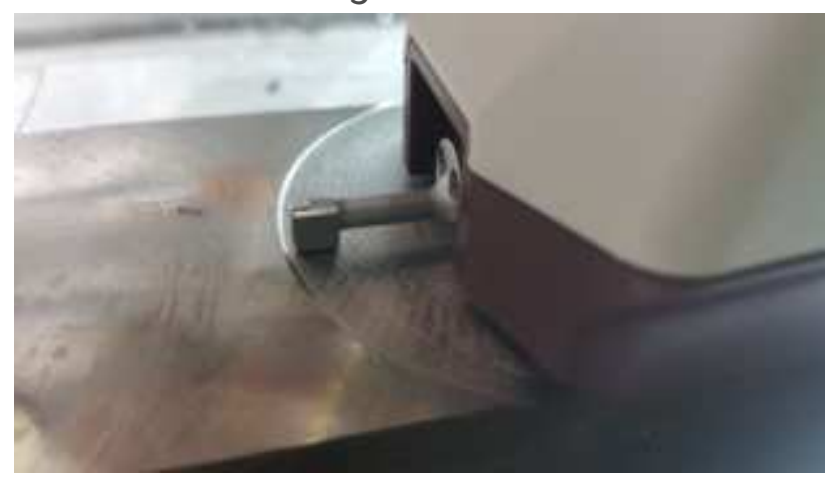

Figure 8

Measurement of surface roughness by using Surftest device SJ-210 


\section{$\operatorname{Ra}[\mu \mathrm{m}]$}

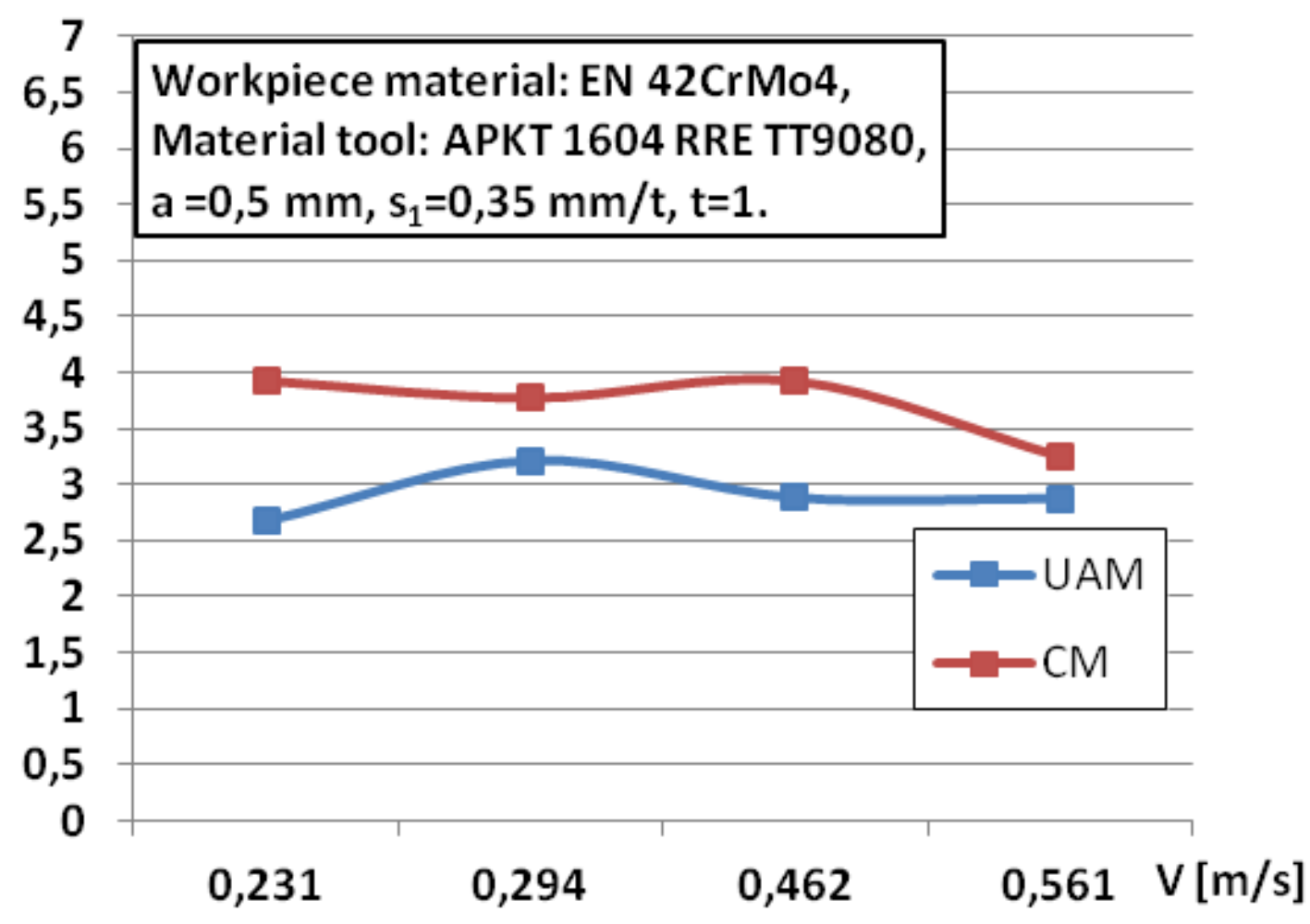

Figure 9

Mean arithmetic roughness Ra as a function of different cutting speeds with a constant feed of 0.35 $\mathrm{mm} / \mathrm{t}$ 


\section{$\operatorname{Ra}[\mu \mathrm{m}]$}

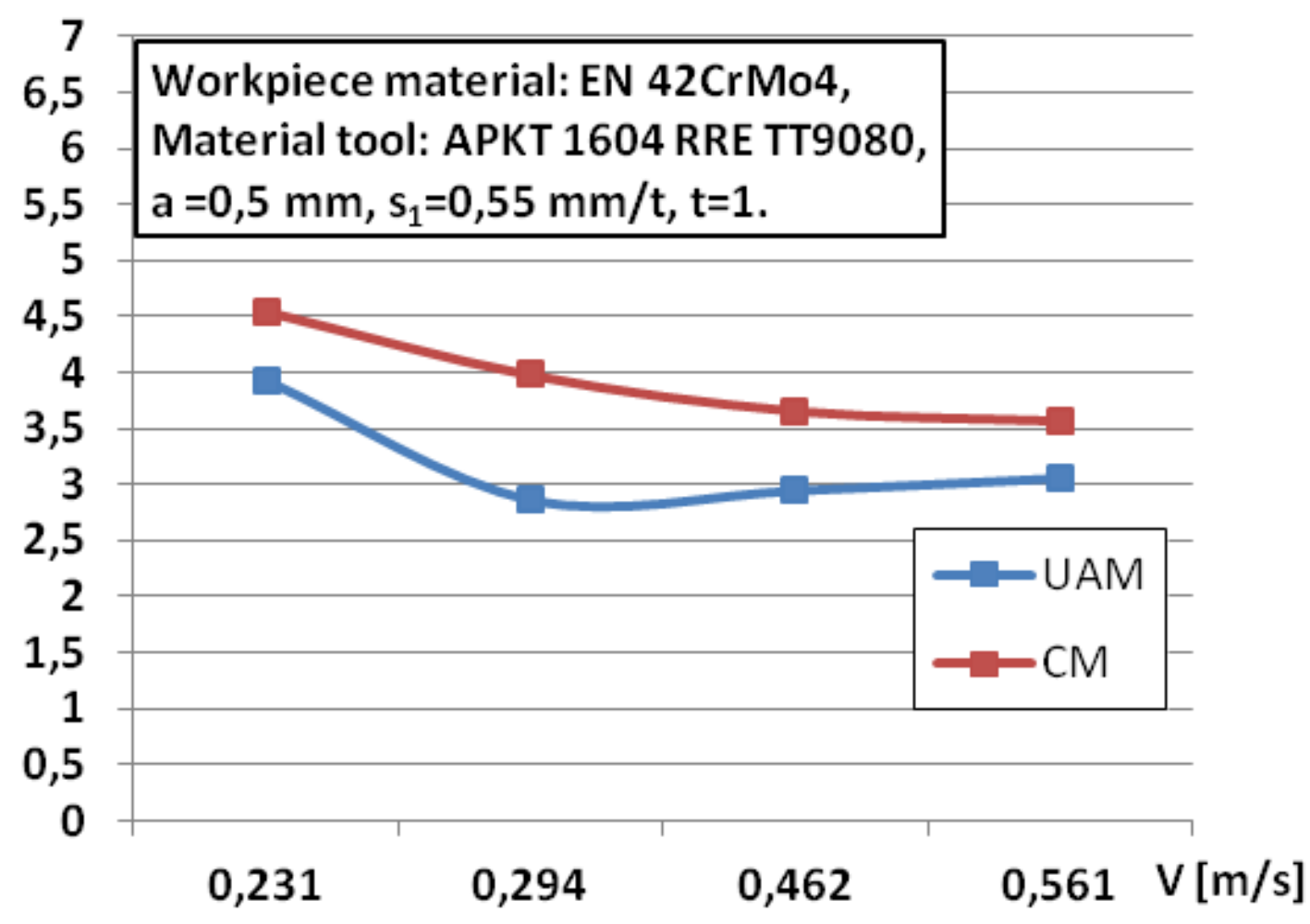

Figure 10

Mean arithmetic roughness Ra as a function of different cutting speeds with a constant feed of 0.55 $\mathrm{mm} / \mathrm{t}$ 


\section{$\operatorname{Ra}[\mu \mathrm{m}]$}

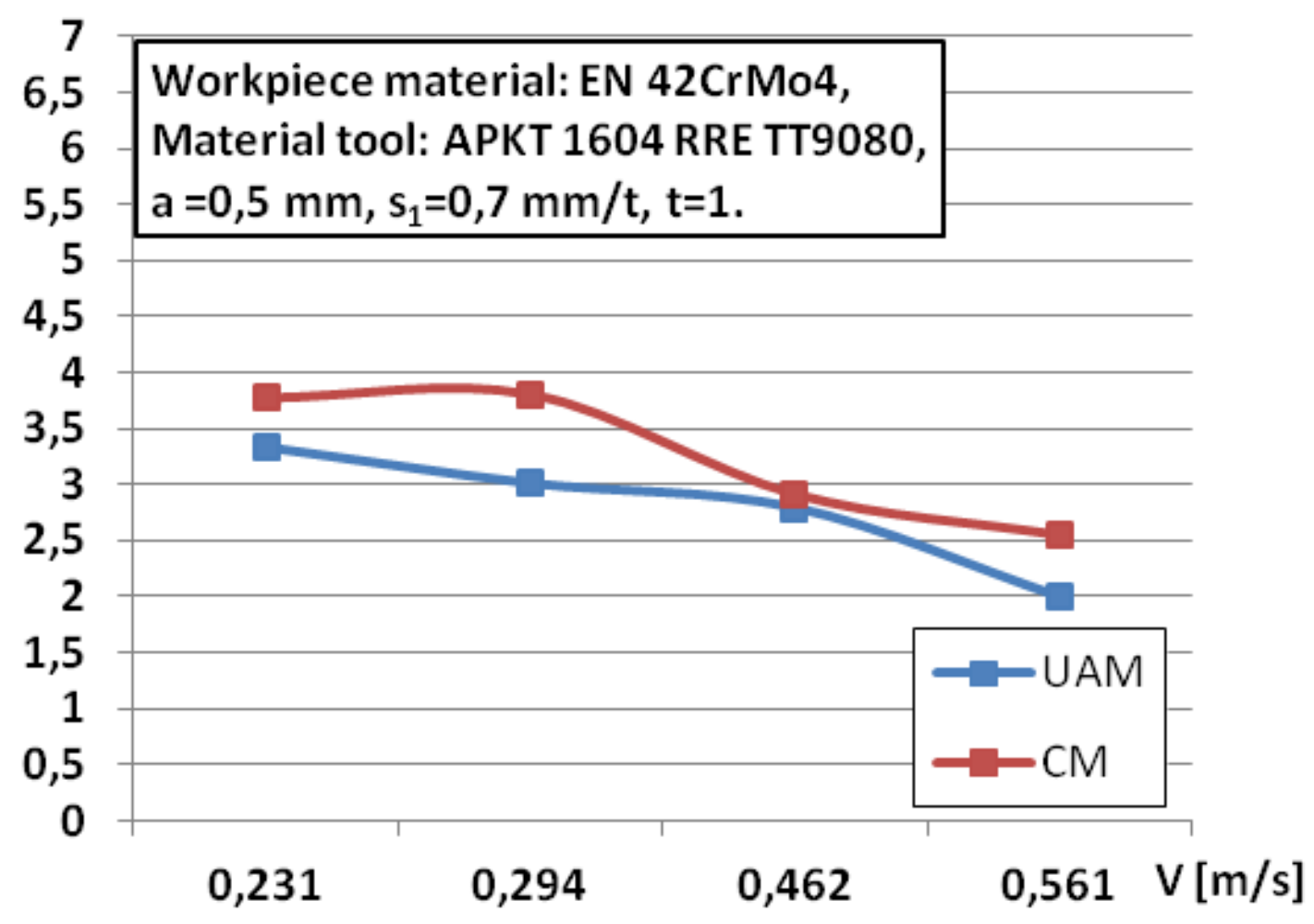

Figure 11

Mean arithmetic roughness $\mathrm{Ra}$ as a function of different cutting speeds with a constant feed of $0.7 \mathrm{~mm} / \mathrm{t}$ 


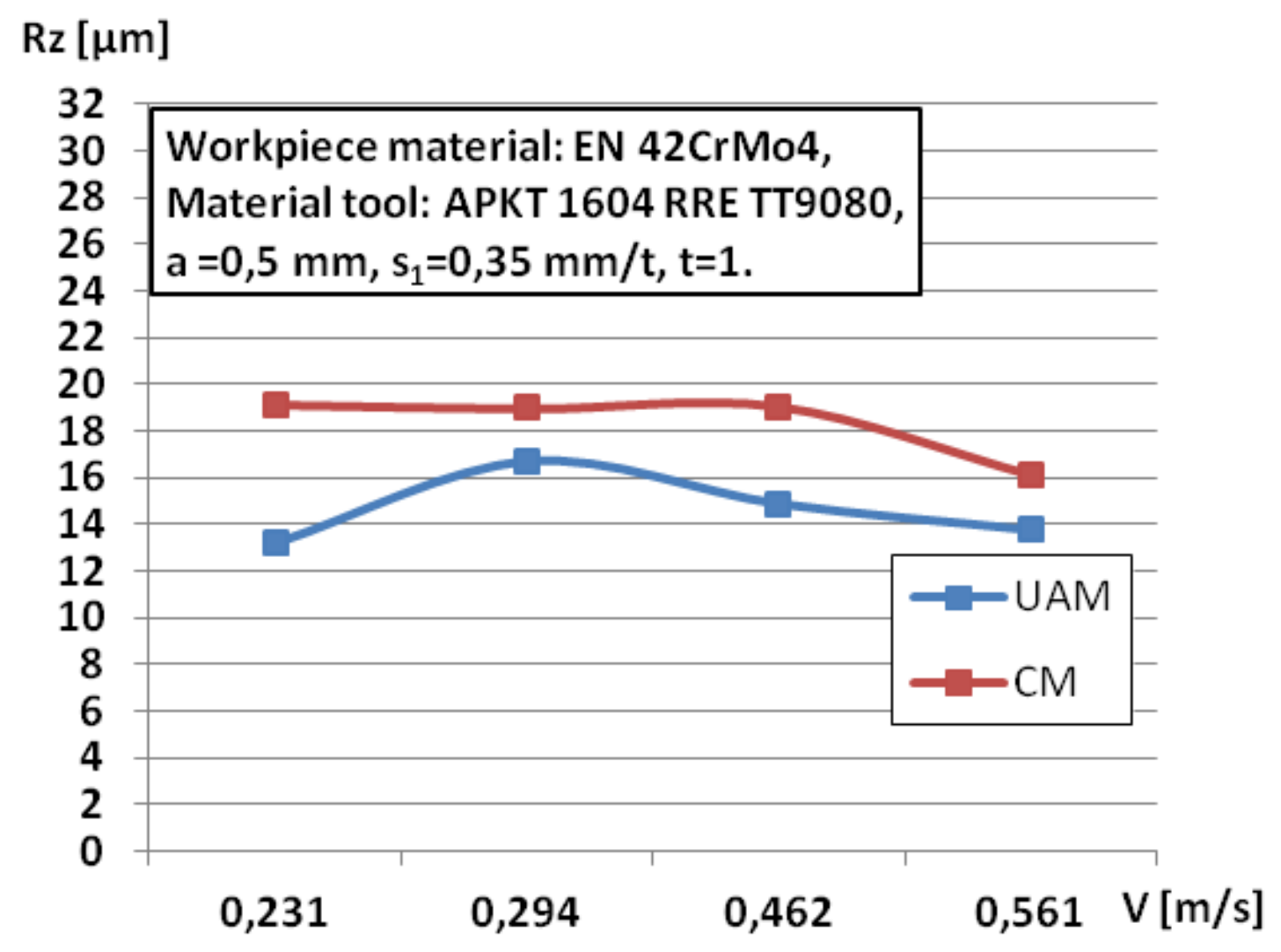

Figure 12

Mean height of unevenness measured at ten points Rz as a function of different cutting speeds with a constant feed of $0.35 \mathrm{~mm} / \mathrm{t}$ 


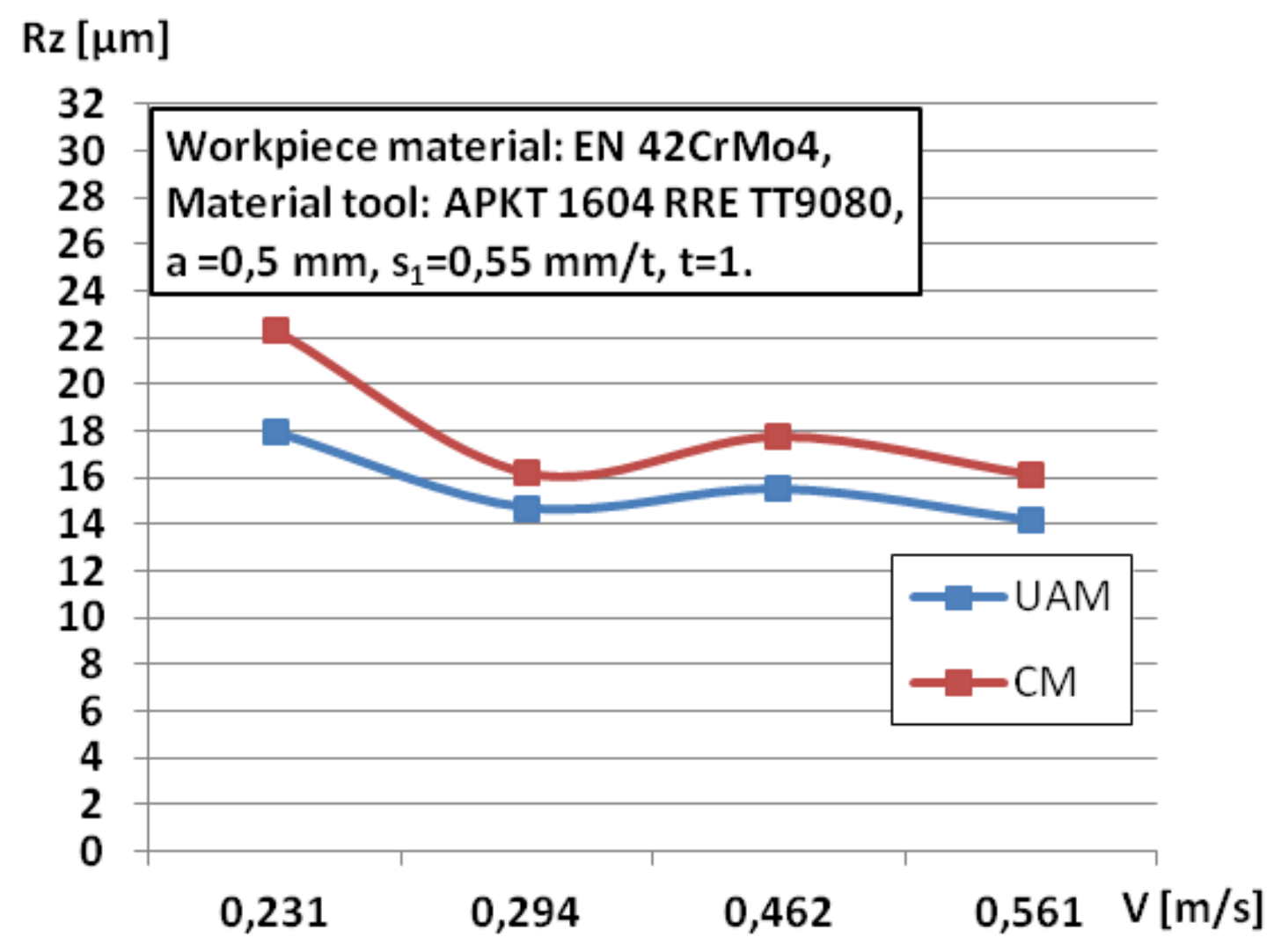

Figure 13

Mean height of unevenness measured at ten points Rz as a function of different cutting speeds with a constant feed of $0.55 \mathrm{~mm} / \mathrm{t}$ 


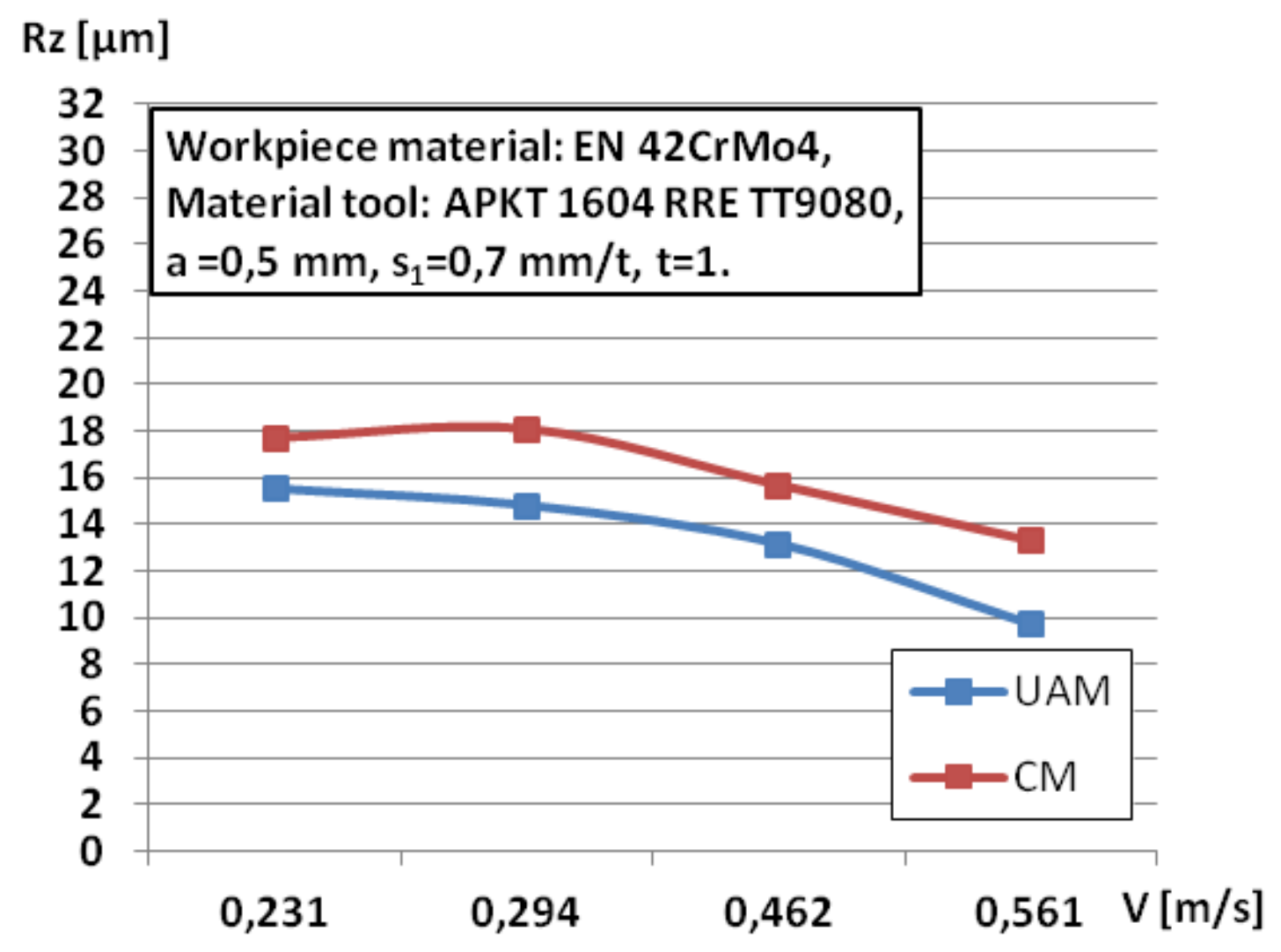

Figure 14

Mean height of unevenness measured at ten points Rz as a function of different cutting speeds with a constant feed of $0.7 \mathrm{~mm} / \mathrm{t}$ 


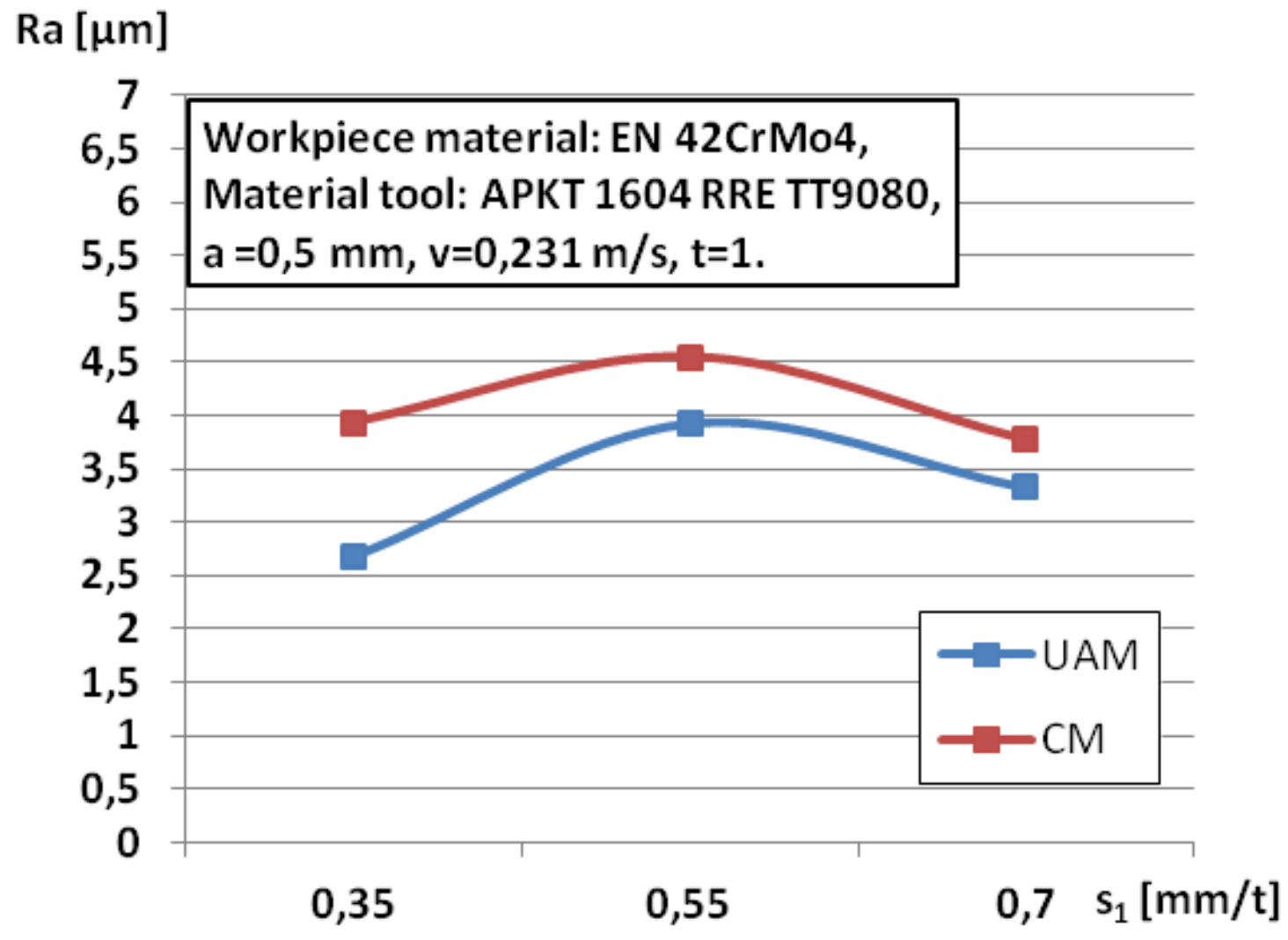

Figure 15

Mean arithmetic roughness $\mathrm{Ra}$ as a function of different feed per tooth and constant cutting speed 


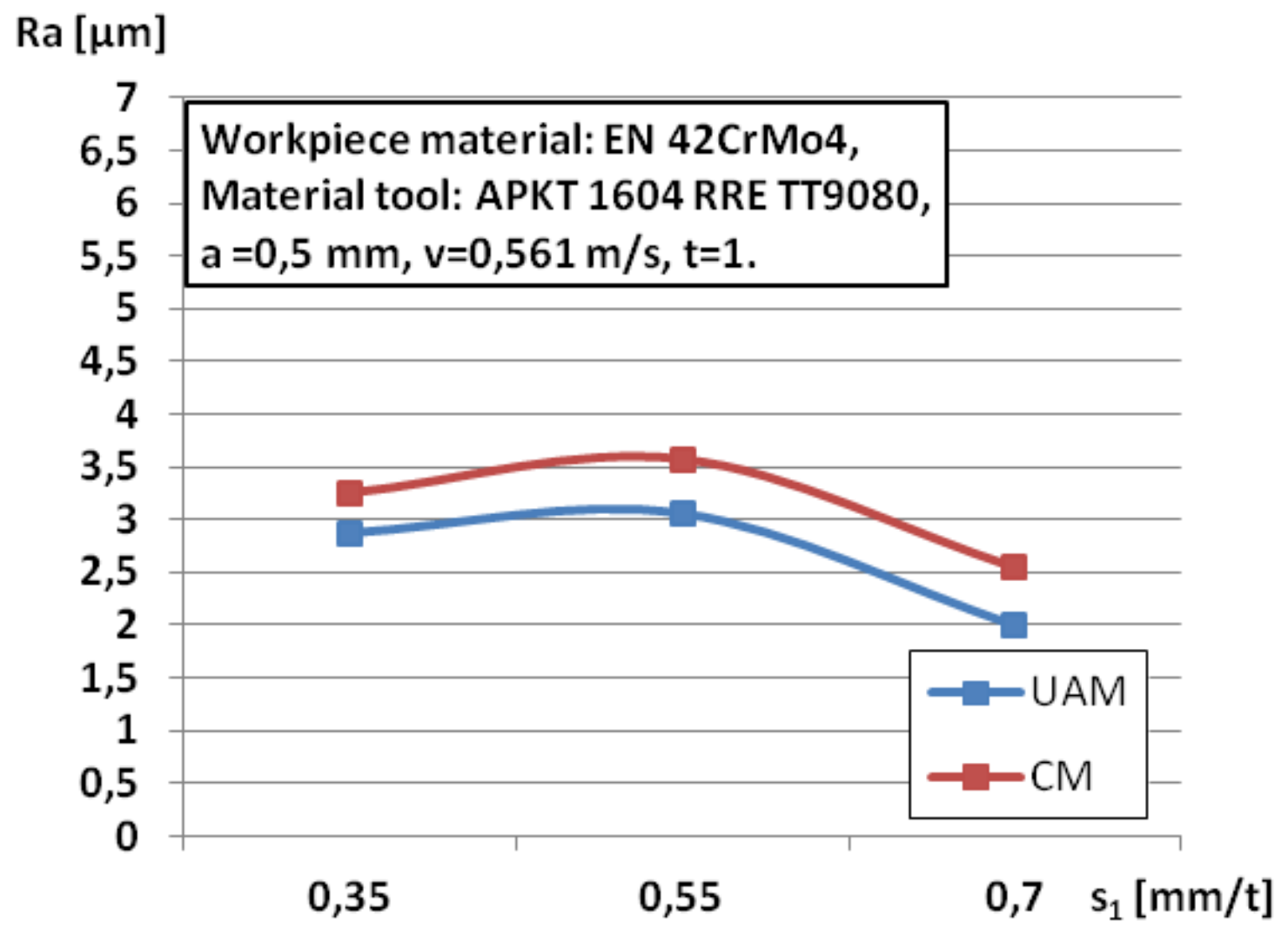

Figure 16

Mean arithmetic roughness $\mathrm{Ra}$ as a function of different feed per tooth and constant cutting speed 